\title{
Role of Collaborative Academic Partnerships in Surgical Training, Education, and Provision
}

\author{
Robert Riviello $\cdot$ Doruk Ozgediz $\cdot$ Renee Y. Hsia $\cdot$ \\ Georges Azzie $\cdot$ Mark Newton $\cdot$ John Tarpley
}

Published online: 5 January 2010

(C) The Author(s) 2010. This article is published with open access at Springerlink.com

\begin{abstract}
The global disparities in both surgical disease burden and access to delivery of surgical care are gaining prominence in the medical literature and media. Concurrently, there is an unprecedented groundswell in idealism and interest in global health among North American medical students and trainees in anesthesia and surgical disciplines. Many academic medical centers (AMCs) are seeking to respond by creating partnerships with teaching hospitals overseas. In this article we describe six such partnerships, as follows: (1) University of California San Francisco (UCSF) with the Bellagio Essential Surgery Group; (2) USCF with Makerere University, Uganda; (3) Vanderbilt with Baptist Medical Center, Ogbomoso, Nigeria; (4) Vanderbilt with Kijabe Hospital, Kenya; (5) University of Toronto, Hospital for Sick Children with the
\end{abstract}

\section{R. Riviello $(\bowtie)$}

Division of Trauma, Burns, and Surgical Critical Care, Harvard

Medical School, Brigham and Women's Hospital, 75 Francis

Street, Boston, MA 02120, USA

e-mail: riviello@post.harvard.edu

\section{Ozgediz · G. Azzie}

Division of Pediatric Surgery, University of Toronto, Hospital for Sick Children, 555 University Avenue, Toronto,

ON M5G 1X8, Canada

\section{R. Y. Hsia}

Department of Emergency Medicine, University of California, San Francisco Medical Center, 1001 Potrero Avenue, San Francisco, CA 94110, USA

\section{Newton}

Department of Anesthesia, Vanderbilt University Medical Center, 3115 VCH 9070, Nashville, TN 37232, USA

\section{J. Tarpley}

Department of Surgery, Vanderbilt University Medical Center, D-4314 Medical Center North, Nashville, TN 37232, USA
Ministry of Health in Botswana; and (6) Harvard (Brigham and Women's Hospital and Children's Hospital Boston) with Partners in Health in Haiti and Rwanda. Reflection on these experiences offers valuable lessons, and we make recommendations of critical components leading to success. These include the importance of relationships, emphasis on mutual learning, the need for "champions," affirming that local training needs to supersede expatriate training needs, the value of collaboration in research, adapting the mission to locally expressed needs, the need for a multidisciplinary approach, and the need to measure outcomes. We conclude that this is an era of cautious optimism and that AMCs have a critical opportunity to both shape future leaders in global surgery and address the current global disparities.

\section{Introduction}

An increasing and unprecedented groundswell of interest in global health exists today among North American medical students and trainees [1]. A great disparity in access to health care services exists between the world's rich and poor-sub-Saharan Africa carries 25\% of the world's disease burden but has only $2 \%$ of the world's human resources for health [2]. The contrast between this great enthusiasm and this great need is profound in the fields of surgery and associated disciplines. Surgical leaders at premier postgraduate training programs in the United States assert that easily half of medical students entering general surgery training today are seeking significant exposure to service in resource-limited settings as a component of their training (Zinner, 2008, personal communication; Warshaw, 2008, personal communication). And yet, sub-Saharan Africa has the highest concentration of surgical disease 
burden [3] but the lowest concentration of surgical and anesthesia providers-with only 1 surgeon per 400,000 people in East Africa $[4,5]$. This deficit prompted global health leaders Paul Farmer and Jim Yong Kim to dub surgery "the neglected stepchild of global public health" [6].

In response to this wave of trainee interest, North American academic medical centers (AMCs), along with other sectors, are seeking to address both the deficit in overseas training in health services and the great unmet need. Many AMCs, both university and non-university affiliated, engage in developing surgical services in resource-limited settings. This article examines the experience of collaborative academic partnerships in the surgical disciplines between four North American AMCs and hospitals in sub-Saharan Africa. These institutions each presented their programs at the 2nd Annual Burden of Surgical Disease Meeting held in Chicago in May 2009. We reflect here on lessons learned, challenges recognized, and values gained from these experiences. Our goal is not to create "road maps" or "models" for other programs but rather to emphasize certain values, priorities, and considerations with which we have grappled.

The term academic partnerships describes a variable set of experiences among a number of different institutions. We do not seek to define it in this presentation, except to say that often the term is used interchangeably with "twinning," and refers to a mutual agreement, more formal than informal, between institutions to accomplish an objective, e.g., education, improving healthcare, or other cooperative effort. The concept of twinning encourages partnerships between high income country universities with resource-challenged institutions in the lower- and middleincome countries. In 2003 a coalition of HIV/AIDS advocacy groups stated that "twinning must be based on the needs of institutions in southern nations," and that "smaller community-based groups" should not be excluded from involvement [7].

Many North American teaching hospitals maintain relationships with overseas institutions. A survey of surgical residency directors conducted by Operation Giving Back (OGB) of the American College of Surgeons (ACS), together with the Association of Program Directors in Surgery (APDS), reveals a broad range of activities among surgical residencies. To date about 55 of the 253 polled have responded. Of these 55, 7 (12\%) programs have formal international rotations for their residents, $11(20 \%)$ plan to initiate "twinning" relationships, and 34 (62\%) have informal rotations [unpublished data]. Some of these are very informal rotations, meaning a faculty member goes overseas occasionally and takes a resident along. Residents involved are usually in their third or fourth (of 5) clinical years, and most of the rotations are trips of about 4 weeks. Issues identified by program directors include funding, credentialing (which varies widely), receiving academic credit, and sometimes safety. Given the polled audience, the information focuses on the North American resident's experience. We argue that while training globally minded North American surgeons is a vital function of these twinning relationships, such training is only one component of many in truly collaborative academic partnerships. In the next section, we briefly describe a few programs in which we have been involved, and we analyze key factors for success in establishing and maintaining these programs.

The UCSF Global Health Science-Bellagio Essential Surgery Group Experience

In 2003, the University of California, San Francisco (UCSF) established the Global Health Sciences (GHS) institute as an organizing body for the multiple global health programs that existed throughout the university [8]. In 2007, members of GHS met with healthcare leaders from sub-Saharan Africa, the Karolinska Institute, and the World Health Organisation (WHO) at a conference in Bellagio, Italy, sponsored by the Rockefeller Foundation. At that meeting surgeons, anesthesiologists, obstetricians, health policymakers, and health economists sought to describe the dearth of surgical care in low-income countries, particularly in sub-Saharan Africa. The Bellagio Essential Surgery Group (BESG) was born out of a collaboration among these leaders. At the second such meeting, held in Kampala, Uganda, in July 2008, the collective group discussed the burden of surgical disease, potential solutions to the lack of surgical services, training modules, and demonstration projects.

The UCSF-BESG offers technical support for African countries who have defined a surgical services research agenda. At present, UCSF-BESG supports research investigating the training of non-physician surgical providers in several African countries. The group also works to disseminate ideas from these model projects at African forums, including the College of Surgeons of East, Central \& Southern Africa (COSECSA). Individuals within the UCSF-BESG network have deepened networks between African providers and Western providers by presenting their work in forums such as the Global Burden of Surgical Disease. The vision of this group is to serve as a catalyst to develop and disseminate new models of care that have the potential to expand surgical access.

\section{The UCSF-Makerere University, Uganda-GPAS experience}

In 2003 an alliance was established between Departments of Surgery at UCSF and Makerere University (MU), and associated Mulago Hospital, in Uganda. This alliance followed from pre-existing university collaboration in 
infectious disease and an existing formal affiliation agreement between the universities. Senior surgical faculty from each institution drafted a memorandum of understanding, outlining goals and specific objectives for a mutually beneficial collaboration [4]. These included clinical rotations for UCSF residents, faculty exchange, research collaborations, and the development of educational resources at MU. In the first 5 years of the collaboration, nine UCSF faculty members visited MU for didactics and collaborative research, one MU faculty member visited UCSF for an observational fellowship, and four UCSF surgery residents visited MU for clinical rotations [9].

This collaboration provided several early insights. Overseas clinical rotations occurring in a resource-limited context for surgery and perioperative care can be valid educational experiences for North American trainees. Exact reciprocity between the two institutions is very difficult to achieve for numerous reasons. Given this reality, it became clearer that projects must involve a multidisciplinary group of stakeholders. As a result, Global Partners in Anesthesia and Surgery (GPAS) was formed as a UCSFaffiliated group by UCSF trainees and faculty and overseas counterparts with a vision toward improving perioperative and surgical services in low-income countries. In Uganda, projects have included providing residency tuition coverage at MU, thereby recruiting more trainees in surgery and anesthesiology [10]. As injury epidemiology and trauma care were high local priorities, a trauma database was established pooling disparate local data sources. This database demonstrated that $24 \%$ of deaths in Kampala were injury-related. In response, two courses were delivered to improve trauma care: (1) a modified advanced trauma care course was incorporated into MU surgical training and (2) a prehospital trauma training program was delivered to lay first responders. Both courses were designed and taught collaboratively. The partnership has also encouraged further research among MU residents and faculty in surgical epidemiology, trauma care, surgical oncology, and health policy and surgical services.

\section{The Vanderbilt-Baptist Medical Centre Ogbomoso, Nigeria experience}

The Baptist Medical Centre Ogbomoso (BMCO) in southwest Nigeria was founded in 1907. The informal partnership between the Vanderbilt University Medical Center (VUMC) and BMCO dates to 1993 when one of the authors (J.T.) returned to Vanderbilt and ultimately became the program director for the surgical residency at Vanderbilt. He and his family spent most of 1978-1993 at BMCO where they welcomed visiting physicians, residents, and medical students. During that era, together with other expatriate and Nigerian physicians, a residency in general practice was developed and approved by the Nigerian College of General Medical Practice, a close equivalent to a family practice residency in the United States, with heavy emphases on surgery and obstetrics \& gynecology. Residents spend 5 postgraduate years training in internal medicine, obstetrics/gynecology, pediatrics, community health, and surgery. By 1993 the residency leadership had been assumed by Dr. OlaOlorun, a BMCO trainee. Anesthesia training for nurses was also offered periodically [11].

Since 1993, yearly trips are conducted by a variable number of physicians from VUMC to BMCO for 2-4 weeks to "water relationships, encourage, and bring specialists" [12]. Visiting specialists have included pediatric surgeons, plastic surgeons, urologists, orthopedists, and anesthesiologists. The goal of these trips is to share knowledge and skills. Visiting surgeons and anesthetists are expected to give didactics for students and residents, and to encourage, assist, and train in the operating room [11]. In recent years, under the Vanderbilt Institute for Global Health, efforts are increasing to formalize this relationship with visiting residents in surgery, visiting medical student researchers, and joint grant funding application.

\section{The Vanderbilt_-Kijabe Hospital, Kenya experience}

This partnership is led by one of the authors (M.N.) who is a pediatric anesthesiologist by training and part of Vanderbilt International Anesthesia. Along with his family, this physician, who has been working at Kijabe Hospital $(\mathrm{KH})$ for 10 years, spends 9 months per year at $\mathrm{KH}$ and 3 months in Nashville at VUMC. Kijabe is a large rural, Christian mission hospital founded in 1915. In the last decade, $\mathrm{KH}$ has seen the growth of parallel tracks in anesthesia and surgical provider training. In 1995, in conjunction with the University of Nairobi, physician training started. Since that time, a total of 55 interns, 12 registrars (2 general surgery, 4 orthopedics, 2 neurosurgery general surgery rotations, 4 family practice), and two fellows in pediatric surgery have been trained. These physician trainees come from several East Africa countries and are trained by 14 consultant surgeons (general surgery, orthopedics, ob/gyn, pediatric surgery, and plastic surgery). In 1998, recognizing the extreme anesthesia shortage nationwide, and the growing need locally, KH established a Kenya Registered Nurse Anesthetist (KRNA) training center in conjunction with the Ministry of Health. This 15-month, competency-based course provides a rich clinical experience culminating in national certifying KRNA exams. $100 \%$ of the Kijabetrained KRNAs continue to work in rural surgical hospitals in central and western Kenya. 
In the last 3 years residents and faculty in anesthesiology from VUMC have rotated at KH under faculty supervision. Residents are expected to arrive prepared to give lectures to the KRNAs and train in clinical care. An open, teachable attitude is also a must-as residents often receive as much from KRNA trainees as they give [13]. As this collaboration moves forward, interest is increasing in formalizing a tripartite partnership between Nairobi University, Vanderbilt University, and Kijabe Hospital as a means to strengthening efforts in education, research, and service.

\section{The University of Toronto, Hospital for Sick Children-Botswana experience}

The Departments of Surgery at the University of Toronto and the Hospital for Sick Children have established a relationship with the Ministry of Health in Botswana. The main focus has been at the two large referral centers: Princess Marina Hospital (PMH) in the capital Gaborone and Nyangabwe Hospital in Francistown. This collaboration began with one surgeon (G.A.) acquiring a Botswana medical license, local credentialing, and a Ministry of Health (MOH) position to work as a surgeon in both institutions for a period of 6 months. This surgeon now spends 3 months a year in Botswana. During the remaining 9 months, he collaborates with local surgeons on clinical development and scholarly activities. To date this partnership focuses on pediatric surgery, pediatric resuscitation, minimal access surgery (MAS), and telesimulation. In the discipline of pediatric surgery, local training at both tertiary care centers is provided for general surgeons in the management of patients with anorectal malformations. Simultaneously, numerous training sessions on pediatric resuscitation (specifically intraosseous resuscitation) for doctors have been completed. Local surgeons specifically requested laparoscopic surgery training. Thus an MAS workshop, which included the Fundamentals of Laparoscopic Surgery (FLS) curriculum, was developed and launched (2005-2009), and a program for OR nurses to attend laparoscopic workshops in South Africa started in 2009 [14]. Telesimulation was developed in response to an ongoing need for mentorship with the FLS course. Using standard FLS simulators and internet Skype connections, 16 local surgeons participated in a 10-week training study. In the cohort mentored via telesimulation, $100 \%$ achieved an FLS simulator certification passing score while only $38 \%$ of participants in the non-telesimulation group were successful [15].

This partnership approaches with caution the creation of an international surgical elective for North Americans. Priority is always placed on the needs and expressed desires of the host institution, the Botswana $\mathrm{MOH}$, officials at the newly created Faculty of Medicine at the University of Botswana, and the health care providers at Princess Marina and Nyangabwe hospitals. At the time of writing, plans are being drawn up for more formal surgical electives with the University of Pennsylvania Surgery Department; as such an arrangement was endorsed by all stakeholders (PMH Department of Surgery, Superintendent of PMH, MOH, University of Botswana, Medical Council of Botswana, the US Accreditation Council for Graduate Medical Education (ACGME), and U Penn). Plans are also in place for guiding the re-patriation of Botswana surgical specialists at various levels of training abroad, as well as the entire training of selected Botswana Medical Officers.

\section{The Harvard Medical School, Brigham and Women's Hospital, Children's Hospital Boston-Partners in Health Haiti and Rwanda experience}

Partners in Health (PIH), a nonprofit organization started in 1987, seeks to bring modern medical care to resourcechallenged communities around the world through the support of health services and the development of accompagnateurs (community health workers). In the last 2 years $\mathrm{PIH}$ formalized relationships with surgeons based at Brigham and Women's Hospital (BWH) and Children's Hospital Boston (CHB). Initially, a global surgery fellowship was established for North American surgeons to work primarily clinically through Zamni Lasante (ZL)-PIH's sister organization in Haiti. The first fellow completed his year in mid 2009. Subsequently a PIH surgical committee was established to coordinate all PIH surgical activities, including advocacy and fundraising, procurement, and recruitment and organization of volunteer general and subspecialty surgeons. Most recently, BWH surgeons established relationships with the PIH-Rwanda (Inshuti $\mathrm{Mu}$ Buzima-IMB) leadership to assist with surgical delivery and training. The request of the Rwandan leadership, supported by findings from needs assessments, is for increased training and skills transfer. At present $\mathrm{BWH}$ surgeons are organizing to provide for year-round training of generalist Rwandan doctors in three IMB-supported rural district hospitals.

As surgical involvement in each of these countries developed, it became increasingly clear that the needs of each differed greatly. In Haiti, ZL has a complement of Haitian general surgeons and obstetrician/gynecologists. What ZL lacks, and where partnership has most benefitted, is the provision of subspecialist services. Under the organization of Haitian surgical leadership visiting subspecialists visit Haiti on a rotational basis 1-2 weeks at a time, 2 3 times per year. Specialties include advanced general surgery, ENT, plastic surgery, breast surgery, pediatric 
surgery, urological surgery, and orthopedics. In Rwanda, there are no surgeons at IMB-supported hospitals and few surgeons nationwide. Thus, BWH efforts are centered on recruiting volunteer general surgeons and obstetricians to provide essential and emergency surgical training for local general practice physicians.

\section{Lessons learned, challenges recognized, and values gained}

In presenting this collection of reflections, we self-consciously recognize that we are all North American physicians involved in international work. As such, the following discussion is necessarily from the point of view of practitioners from wealthy countries. However, we also acknowledge that our views have been molded by our African colleagues as they have hosted us in this work together.

The importance of relationships

Relationship-building and developing understanding takes time. Mutual trust and respect are goal outcomes of such investments and are indispensable to building an educational program. In Chinua Achebe's oft-cited work Things Fall Apart [16], he depicts how our relationships in community are critically important to our culture. And he demonstrates what happens when there is an invasion of egoism: society becomes atomized and loses cohesion. Persons end up thinking about themselves, hyperindividualistically as opposed to thinking about family, clan, and community. The importance of connecting with and relating to our host colleagues on a personal as well as a professional level cannot be overemphasized. Joy and satisfaction in this work come in the context of relationships and the strength of those bonds.

\section{Mutual learning}

Relationship and mutual respect is foundational for partnership learning. Paulo Freire's Pedagogy of the Oppressed [17] demonstrates this principle. A Brazilian expert in adult literacy, Freire went to the Amazon rain forest to teach peasants to read. He did not know how to survive in the rain forest, but his students knew well. Knowledge was shared: he survived, they learned to read and write. When expatriate health professionals visit a host institution, a similar dynamic is at work. We offer technical expertise: clinical skills, research skills, and educational skills. Our host colleagues provide contextual expertise, essential for long-term impact: an understanding of local burden of disease, of local perception of illness, and of the complexities of societal, cultural organization. Also, the lessons learned working overseas with vulnerable populations may be applicable to similar North American populations facing disparities in access to surgical care.

Need an advocate

A clear commonality in the partnerships described here and elsewhere is the need for advocates. In each case the job description of the advocate varies; however, it's clear that each side of the partnership needs people who are capable and culturally sensitive, and who demonstrate sustained commitment. In our experience, one essential promoter is based in the North American academic partner. Usually this person's role is to maintain communication between institutions, to support and guide individuals or teams travelling between institutions, and usually to be a catalyst for broadening relationships. In our more developed partnerships (UCSF-MU, Vanderbilt-Kijabe, and Harvard-PIH Haiti) a promoter in the host institution fulfills similar functions as well as providing direction and guidance to projects and programs. This experience is also reflected in the Brown Medical School/Tenwek Hospital partnership, which "works well, but requires permanent surgical faculty in Africa" [18]. One ongoing challenge lies in identifying and supporting that local advocate. The associated reality is that programs based on a small group of individuals may have challenges in sustaining themselves if dependent only on these individuals.

Across the board, the centrality of the advocate appears to be critical to current successful efforts. Our expectation and hope are that as twinning partnerships mature, these relationships will become increasingly networked social webs, rather than hub-and-spokes. Then they can truly become institutional partnerships, with robust involvement and investment, and not subject to the movements of individuals from one institution to another. Perhaps, if this current generation of students and trainees can maintain their unprecedented enthusiasm for global health, they will become the foundation of such future institutional partnerships.

Local training needs supersede expatriate training needs

Tension may develop between the perceived needs of local trainees and those of North American trainees. The development of a healthy partnership requires that this tension be recognized. It may come to a head if visiting trainees are "doing all the good cases" to the exclusion of local trainees. It may present when research agendas are driven by visiting physicians rather than by a collaborative approach. It is our view that if we accept several underlying assumptions, then navigating these potential conflicts 
of interest becomes simpler. The first assumption is that, on principles of justice, "twinning must be based on the needs of institutions in southern nations" [7], as stated above. The second is that ultimately, local problems will require local solutions.

The primary roles of visiting surgeons and anesthesiologists should be as trainers, advocates, and encouragers whenever possible, rather than as the ones "doing the cases." Certainly we also have a secondary mandate to train the next generation of North American providers with career goals in global health. It is our belief that expatriate trainee involvement in international academic partnerships should be encouraged. But it should be clear that the trainee's involvement, just like the North American faculty member's role, should augment, not detract from, local training, development, and solidarity.

\section{Research coalitions}

"Legitimate academic experiences improve the success of these programs" [9]. Encouraging research collaboration between partnered institutions should happen at all levels-students, trainees, and faculty. Projects should involve all invested parties at each step. Conceptualizing research questions and methods, project execution, writing and reporting, and receiving credit should be shared. By encouraging our overseas colleagues in academic pursuits, we contribute to the development of long-term local health care development and delivery. Vigorous coalitions, particularly between universities and groups working in similar countries may minimize redundancy and maximize the possibility to meet local needs. The Bellagio Essential Surgery Group offers a good example. Via this coalition the Northern institution (UCSF) has been able to facilitate South-South collaboration (in this case, in researching the training on non-physician surgical providers).

\section{Adapting the mission to the locally expressed needs}

Some or all of our preconceived notions about the content of our work have been modified by the expressed desires of our local colleagues. In Botswana it meant creating a laparoscopic training program when the initial goal was to train others in open pediatric general surgery. In Haiti it meant shifting from longer-term generalist surgeon recruitment to short-term visiting subspecialist trips. In Uganda it meant locally adapted trauma courses and resources to refurbish existing equipment rather than importing new equipment. These initiatives were each driven by understanding the local context which our local colleagues were able to articulate and we as visitors may never have identified. Determining the most "contextappropriate" intervention has long been a challenge in global surgical work. We believe these questions are best answered in context of dialogue and partnership.

Multidisciplinary approach

As stated by Heuric Rokotomalala, a Madagascan surgeon at Kijabe, "Anesthetists and surgeons are like rice and water: together in the rice-field, together in the pot, and always complementary for a common goal" [19]. Surgery, at its best, is a team effort involving anesthesia providers, surgical providers in their multiple disciplines, nursing, and OR support staff. The experiences at Makerere, Kijabe, and Ogbomoso clearly support the synergistic effect of concurrent anesthesia and surgical provider training. While it may often be true that partnerships start as relationships within a single discipline, over time efforts need to be made to link across departments of surgery, anesthesia, and nursing to maximally develop perioperative services for improved patient care and safety. This can also extend to collaborations with medical, pediatrics and infectious disease disciplines.

\section{Is this Academic?}

We have discussed much about partnerships, but have not much touched academics. Most academic centers subscribe to the triple commitments of service, education, and research. Recently, attention has been placed on resurrecting the classic Oslerian "triple threat" physician in the context of global health by encouraging social responsibility among physician researchers [20]. Investment in these partnerships has the potential for meeting the academic mandates. The service and the training components have been clearly outlined. The research components can have many paths. A valuable research path in the context of partnerships is in metrics. We need to be able to demonstrate that there is value added in training and service. This requires measuring effects, outcomes, and changes in the local situation. What are the best metrics to measure impact? Perhaps we can learn from the more seasoned academic partnerships in the infectious diseases community? Or from those in the NGO and humanitarian communities with long-standing operational research experience (e.g., PIH and Médecins sans Frontières)? Ultimately the burden will be on those of us in academics to demonstrate that these twinning programs improve surgical access and quality, reduce disparities, and strengthen health systems.

\section{Conclusions}

We believe this is an era of cautious optimism. The global disparities in distribution of surgical disease and surgical 
access are becoming increasingly evident. However, a tsunami of idealism exists among the next generation of surgical and anesthesia providers in North America that are looking for a place to light, to contribute, to work. As North American AMCs explore twinning relationships with hospitals in sub-Saharan Africa and elsewhere, it is imperative that partnerships be designed thoughtfully to foster the development of these future leaders in global surgery, all the while prioritizing local capacity-building.

If you plan for a year, plant a seed.

If for 10 years, plant a tree.

If for 100 years teach the people.

-Confucius

Open Access This article is distributed under the terms of the Creative Commons Attribution Noncommercial License which permits any noncommercial use, distribution, and reproduction in any medium, provided the original author(s) and source are credited.

\section{References}

1. Kanter P (2008) Global health is more important in a smaller world. Acad Med 83:115-116

2. Rogers S (2008) Disparities in surgery: access to outcomes. World J Surg 32:505-508

3. Debas H, Gosselin R, McCord C, Thind A (2006) Surgery. in Disease Control Priorities in Developing Countries. 2006. World Bank, Washington, DC, pp 1245-1260

4. Galukande M, Kijambu S, Lubogoa S (2006) Improving the recruitment of surgical trainees and training of surgeons in Uganda. East Central Afr J Surg 11:17-24

5. Blanchard RJW, Merrell RC, Geelhoed GW, Ajayi OO , Laub DR, Rodas E (2001) Training to serve unmet surgical needs worldwide. J Am Coll Surg 193:417-427

6. Farmer P, Kim J (2008) Surgery and global health: a view from beyond the OR. World J Surg 32:533-536

7. Infectious Disease Society. Letter to Drs. Carrino, McCray, and Goldman of Global AIDS/HIV. 2003 [cited 2008 May 19, 2008]; Available at http://www.idsociety.org/Content.aspx?id=1292
8. Macfarlane SB, Agabian N, Novotny TE et al (2008) Think globally, act locally, and collaborate internationally: global health sciences at the University of California, San Francisco. Acad Med 83:73-179

9. Ozgediz D, Wang J, Jayaraman S, Ayzengart A, Ayzengart R, Lipnick M, Mabweijano J, Kaggwa S, Knudson M, Schecter W, Farmer D (2008) Surgical training and global health: initial results of a 5-year partnership with a surgical training program in a low-income country. Arch Surg 143:860-865

10. Global Partners in Anesthesia and Surgery Homepage. 2008 Available from: www.globalpas.org. Accessed 19 June 2009

11. Tarpley J, Tarpley M, Meier D, Meier P (2007) Operating in the global theater. Surg Rounds 11:509-517

12. Tarpley J (2009) An alternative vacation: an overview of surgery in Nigeria 1978-2009. In MGH Surgical Grand Rounds, Boston

13. Vanderbilt International Anesthesia (2009) http://www.vandy dreamteam.com/vanderbilt_international_anesthesia. Accessed 19 June 2009

14. Okrainec A, Smith L, Azzie G Surgical simulation in Africa: the feasibility and impact of a 3-day fundamentals of laparoscopic surgery course. Surg Endosc (e-pub ahead of print, April 3, 2009)

15. Okrainec A, Henao O, Azzie G (2009) Telesimulation in Africa: an effective method for teaching the fundamentals of laparoscopic surgery in developing countries. Surg Endosc 23:S149

16. Achebe C (1958) Things Fall Apart. William Heinemann Ltd, London

17. Freire P (1970) Pedagogy of the Oppressed. Continuum Publishing Company, New York

18. Klaristenfeld DD, Chupp M, CioffiWG, White RE (2008) An international volunteer program for general surgery residents at Brown Medical School: the Tenwek Hospital Africa experience. J Am Coll Surg 207:125-128

19. Newton M (2009) Impact of parallel anesthesia and surgical provider training in sub-Saharan Africa: a model for a resource poor setting. In Global burden of surgical disease working group, 2nd annual meeting, Chicago, May 20-22, 2009

20. Manabe YC, Jacob ST, Thomas D, Quinn TC, Ronald A, Coutinho A, Mayanja-Kizza H, Merry C (2009) Resurrecting the triple threat: academic social responsibility in the context of global health research. Clin Infect Dis 48:1420-1422 